\title{
General Editor's Note: Antitrust and Regulatory Update
}

\author{
Lawrence J. White ${ }^{1}$ D
}

Accepted: 21 October 2021 / Published online: 28 October 2021

(c) The Author(s), under exclusive licence to Springer Science+Business Media, LLC, part of Springer Nature 2021

This issue marks the 20th year of a special feature of the Review of Industrial Organization: "Antitrust and Regulatory Update". As was true in recent years, I asked the Chief Economists of the U.S. Department of Justice's Antitrust Division (DOJ), the Federal Trade Commission (FTC), the Federal Communications Commission (FCC), the DG Competition of the European Union (DGComp), and the Competition and Markets Authority (CMA) of the UK to write essays about the interesting aspects of the important antitrust and regulatory issues that confronted their agencies during this past year. I am pleased to report that all five individuals responded affirmatively.

The essays in this issue of the Review - all of them co-authored with career economists at their respective agencies-are thus the products of all five of their affirmative responses.

As has been reflected in previous years' essays from the competition agencies, mergers (which, of course, include acquisitions) and merger policy continue to be important. In a first for this annual series of essays, two of the agencies-the DOJ and the CMA-discuss their challenges to the same merger: Sabre's proposed acquisition of Farelogix. In addition, the CMA describes its revisions to its Merger Assessment Guidelines, while the DOJ discusses its challenge to another important merger: Visa's proposed acquisition of Plaid. The DGComp essay includes its analysis of the proposed Danfoss/Eaton merger. And the FTC discusses its challenge to a proposed joint venture-which usually requires the same analytical framework as is used for mergers - by two coal companies in Wyoming's Powder River Basin.

The Covid-19 pandemic also drew the attention of the agencies: The FCC discusses its heightened efforts at expanding broadband access in the wake of the pandemic, while the DGComp essay describes that agency's review of state-aid measures that were related to the pandemic.

In the area of consumer protection regulation, the CMA writes about its investigation of the funeral industry, while the FTC discusses its analysis of multi-level

Lawrence J. White

Lwhite@stern.nyu.edu

1 Department of Economics, Stern School of Business, New York University, 44 West 4th Street, New York, NY 10012, USA 
marketing arrangements. In addition, the DGComp essay describes the European Union's proposed Digital Markets Act (DMA), and the FCC essay describes that agency's design of electromagnetic spectrum auctions.

This brief summary cannot, of course, do adequate justice to the interesting analyses and discussions that are to be found in all five essays in this issue; but I hope that I have sufficiently stimulated the curiosity and interest of readers so as to encourage them to read the complete essays. As has been true in past years, RIO readers will find that reading these essays at greater length will be well worth their time.

Publisher's Note Springer Nature remains neutral with regard to jurisdictional claims in published maps and institutional affiliations. 